\title{
Effect of Diffuser and Volute on Turbocharger Centrifugal Compressor Stability and Performance: Experimental Study
}

\author{
H. Mohtar, P. Chesse, D. Chalet, J.-F. Hetet and A.Yammine \\ École Centrale de Nantes, 1 rue de la Noë, 44321 Nantes - France \\ e-mail: mohtar.hani@gmail.com - pascal.chesse@ec-nantes.fr - david.chalet@ec-nantes.fr - jean-francois.heteł@ec-nantes.fr \\ anthony.yammine@ec-nantes.fr
}

\begin{abstract}
Résumé - Effet du diffuseur et de la volute sur la performance et la stabilité d'un compresseur centrifuge de suralimentation: étude expérimentale - Le "downsizing" moteur est potentiellement l'une des stratégies les plus efficaces pour baisser la consommation carburant. Un problème majeur du "downsizing" à l'aide d'un turbocompresseur est la petite plage de fonctionnement stable du compresseur centrifuge à haute pression de suralimentation. Plusieurs techniques ont été étudiées pour augmenter la plage de fonctionnement du compresseur, sans sacrifier le rendement du compresseur. Cet article présente l'effet de la stabilisation du diffuseur sur la performance du compresseur et la ligne de pompage. Deux techniques différentes ont été étudiées, les sillons et le pincement diffuseur. De plus, l'effet de la diminution du bec de la volute sur les performances du compresseur a également été étudié. Le pincement du diffuseur a déplacé la ligne de pompage pour de faibles débits. Ce déplacement a été accompagné par une chute de pression et de rendement. Par ailleurs, des résultats intéressants ont été obtenus en utilisant un diffuseur avec des sillons, qui a permis d'augmenter la pression à débit élevé, et de déplacer la ligne de blocage vers le haut débit. Finalement, la modification du bec de la volute est intéressante dans l'amélioration de l'efficacité du compresseur et du taux de compression à grande vitesse.
\end{abstract}

\begin{abstract}
Effect of Diffuser and Volute on Turbocharger Centrifugal Compressor Stability and Performance: Experimental Study - Engine downsizing is potentially one of the most effective strategies being explored to improve fuel economy. A main problem of downsizing using a turbocharger is the small range of stable functioning of the turbocharger centrifugal compressor at high boost pressures. Several techniques were studied to increase the compressor operating range without sacrificing the compressor efficiency. This paper presents the effect of delaying diffuser stability on the compressor performance and surge line. Two different techniques were investigated, these are grooved and pinched diffuser. Moreover, the effect on retracting volute tongue on compressor performance is also studied. Pinched diffuser shifted surge line to low flow rates, while dropping pressure through compressor. On the other hand, some interesting results were obtained when using grooved diffuser, these are pressure increase at high flow rates, and choke line shift to high flow rates. While retracting volute tongue was interesting in improving compressor efficiency, and pressure lines at high speed.
\end{abstract}




\section{INTRODUCTION}

Downsizing is one of the key measures used to improve the fuel consumption. While downsizing demands a high pressure ratio from the compressor, unfortunately increasing the pressure ratio tends to reduce the compressor map width by a shift of the surge line toward high flow rates and the choke line to low flow rates due to high fluid velocities.

The literature lists different variable and fixed geometry techniques, adopted in turbocharger compressors for increasing map width and studies their effect on the compressor performance.

For delaying compressor stability, hence shifting the surge line to low flow rates at the compressor inlet, imposing prerotation into the incoming air at the compressor inlet is almost used: aerodynamically by injecting air at some oblique angle [1], using radial variable guide vanes [2], axial variable guide vanes [3-5], flexible guide vanes [6], and other swirl generators [7]. In some studies the diffuser was varied by moving side walls [8].

For delaying impeller stability, the fixed geometry approach of casing treatment with the slotted cover [9] is the most successful for turbocharger applications. This grooved or slotted cover, referred to as Map Width Enhancer (MWE) helps to improve the surge margin by recirculating the reverse flow to the impeller inlet when surge is eminent by suppressing the onset of compressor stall (delaying impeller stall), and improves the choke line by allowing additional air into the compressor. This technique has been tested by other authors $[10,11]$ and the results announced correlate with those of Fischer [9].

Even though a vast amount of literature is available on vaneless diffusers stability in centrifugal compressors, there is a lack of information about the effect of the pinch and grooves on the turbocharger centrifugal compressor performance.

Approaching diffuser stall, the radial velocity is much smaller than tangential velocity. Increasing stall critical angle can be done by either decreasing tangential component or increasing the radial one or the two at the same time. Pinches or grooves are almost used to increase radial velocity and reduce tangential velocity, respectively.

Pinches were tested in turbocharger compressors by Abdelhamid and Bertrand [12], who has introduced sharp edge throttle rings at the exit of the diffuser, reducing the diffuser exit width and hence increasing radial component. The use of the throttle rings had stabilizing effect at low flow rates where the compressor was normally subject to flow oscillations. However, the use of throttle rings in normal operating range led to a reduction in overall efficiency.

Moreover, Turunen-Saaresti et al. [13] have studied experimentally different pinch configuration at the shroud and hub sides. He concluded that pinch on the shroud side was the best, and recommended small amount of pinch for better diffuser performance. Moreover, he concluded that highly pinched diffusers increase rotor efficiency. However, he did not mention any effect of pinch on surge line improvement.

Ludtke [14] studied a $47 \%$ reduced diffuser width, he concluded that diffuser pinch lowers choke, and surge limits together with peak efficiency. Moreover, pinched diffuser shifts peak efficiency points to near surge line.

Di Liberti et al. [15] carried out experiments on 2 different diffuser widths at three different speed lines. Author concluded that the narrower of the two diffusers had better efficiency and total-to-total pressure ratio, except at low speed, where an almost identical total-to-total pressure ratio was obtained. The authors also noted that the diffuser width did not influence the overall performance of the impeller.

On the other hand, grooves were not tested on turbocharger compressor. Kurokawa et al. [16] explained theoretically the effect of these grooves, he concluded that using $J$-grooves increases diffuser inlet angle.

CFD analysis was conducted by Gao et al. [17] showed that the inlet flow angle especially that near the wall is significantly increased due to the groove inward flow. This increase is due to a decrease in the tangential velocity but also an increase in the radial velocity. Gao et al. [17] concluded that grooves should be mounted at the separation zone in the diffuser walls and that the radial separation range determines the groove length.

Very limited literature in the turbocharger compressor volute has been reported in the open literature. We note the work done by Eynon and Whitfield [18] on the volute of a turbocharger centrifugal compressor. Authors studied the effect of volute on the overall turbocharger compressor performance, and show that the volute performance is a function of inlet flow angle and that it plays a significant role in setting both the best efficiency flow rate and the operating range of the compressor.

Lipski [20] and Dong et al. [19] studied the volute tongue of a centrifugal pump. Lipski considered that the pump head efficiency is strongly dependant on the position and shape of the tongue. In addition, the force on the tongue becomes zero at point of maximum efficiency. Author proposed adjusting tongue angle and length to control pump performance, and suggested that the tongue should be shortened if an increase in the efficiency at off design conditions is required (especially at high flow rates). On the other hand, Dong et al. [19], studied the effect of retracting and rounding the volute tongue on the centrifugal pump performance. He concluded that pump head was increased at low and high flow rates when retracting the tongue. Moreover, author reported a noise decrease due to tongue moved away from the impeller.

This article is organized as follows: increasing radial velocity component in the diffuser using pinches and its effect on compressor overall performance and surge line, is given in the first part. In the second part, the effect on the compressor performance of decreasing the tangential component using 
radial shallow grooves mounted in the diffuser casing wall, is studied. Finally, the effect of retracting volute tongue on compressor performance in the last part.

\section{EXPERIMENTAL FACILITY}

The turbocharger test rig located at the Laboratory of Fluid Mechanics at the École Centrale de Nantes is shown in Figure 1 . The efficiency and the map extension of the compressor using the different diffuser and volute configurations, were measured in this facility.

The test turbocharger was a KKK variable geometry turbocharger. The turbocharger compressor employs a back swept impeller and 12 radial blades at exit: six of them were short splitters. Geometrical and aerodynamic parameters of the tested compressor are presented in Table 1.

The turbine flow was driven by two electric heaters, which allow the regulation of the turbine inlet temperature. An electric valve controls the turbine expansion ratio and air mass flow at the turbine inlet. Air was drawn through the test rig by a screw compressor with maximum pressure of 7.5 bar and maximum flow rate of $0.24 \mathrm{~m}^{3} / \mathrm{s}$. The compressed air is filtered using a $405 \mathrm{CF}$ (Carbon Filter) and dried before the turbine inlet. Air is then exhausted outside by an extractor fan. At the compressor outlet, an electric valve controls the pressure ratio and air mass flow. An oil pump lubricates the turbocharger. A pressure regulator is added to the turbine inlet line to avoid pressure overshooting.

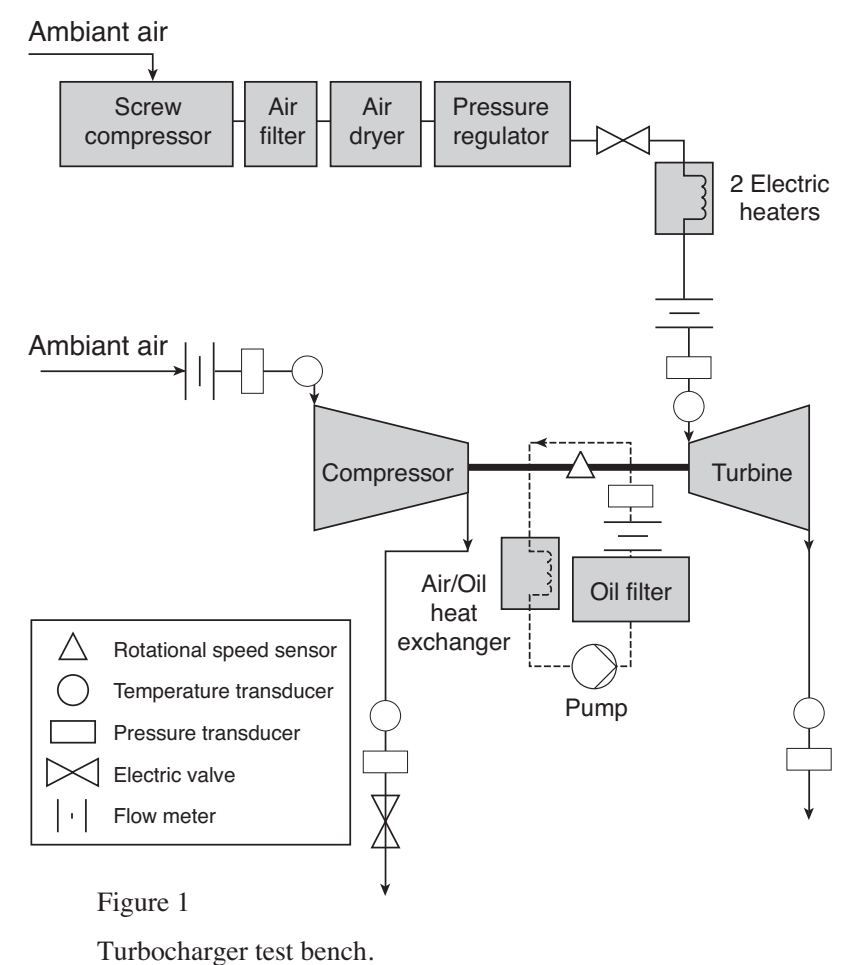

TABLE 1

Geometric and aerodynamic parameters of tested compressor

\begin{tabular}{c|c}
\hline Impeller exit diameter & $46 \mathrm{~mm}$ \\
\hline Impeller tip width & $2.55 \mathrm{~mm}$ \\
\hline Impeller tip to hub ratio & 2.8 \\
\hline Number of blades & $12(6$ splitters $)$ \\
\hline Diffuser area distribution & Const. \\
\hline Diffuser radius ratio & 1.17 \\
\hline Average exit blade angle (with tangent) & $40.7^{\circ}$ \\
\hline Circumferential Mach number & 1.08 at $N=150 \mathrm{~K} \mathrm{rpm}$ \\
\hline Volute exit diameter & $30 \mathrm{~mm}$ \\
\hline
\end{tabular}

The mass flow rate was measured by a thermal flow meter. The compressor rotational speed was measured by means of an inductive sensor, temperature was measured using thermocouples located in the compressor entry and delivery lines while piezo-resistive sensors were installed to measure inlet and outlet static pressures. Measurements were done according the SAE test standards [21].

Experiments were repeated two times to ensure results. Types, calibrated range and accuracy of different transducers used in these experiments are shown in Table 2. Measured uncertainties depend on the compressor speed and mass flow rate. For pressure ratio, uncertainty goes to $1.1-1.3 \%$ of the measured value. For efficiency, the values is around 3\% for mid speed lines, and goes more for higher pressure ratios. The uncertainties of different calculated a measured parameters on the used test bench are detailed in Mohtar et al. [22].

Compressor total pressure ratio and total-to-total isentropic efficiency as function of corrected mass flow rate were obtained by reducing the compressor flow rate by the mean of an electric valve located at the compressor entry while maintaining the electric valve at the turbine entry at constant position. The turbine inlet temperature was fixed to $150^{\circ} \mathrm{C}$.

Surge limits were detected via a frequency based criterion, in the pressure spectrum (analyzing the pressure downstream of the compressor), the frequency peak which describes the surge was between 18 and $22 \mathrm{~Hz}$.

\section{DELAYING DIFFUSER INSTABILITIES}

\subsection{Effect of Pinched Diffuser on Compressor Performance and Surge Line}

Installing pinches in the shroud side of the diffuser has two main objectives:

- to study the effect of suppressing vaneless diffuser instabilities on surge line, pressure and isentropic efficiency of the turbocharger centrifugal compressor. Instabilities suppress was obtained by increasing radial velocity in the vaneless diffuser by mounting pinches in its shroud side; 
TABLE 2

Manufacturer specification for each sensor

\begin{tabular}{|c|c|c|c|c|}
\hline Sensor & Type (model) & Calibrated range & Accuracy, $\Delta$ & Uncertainty, $\delta$ \\
\hline Temperature $(T)$ & $K$ type thermocouple & $0-1000^{\circ} \mathrm{C}$ & $\pm 1 \mathrm{~K}$ & \\
\hline \multirow{5}{*}{ Pressure $(P)$} & \multirow{5}{*}{$\begin{array}{c}\text { Piezoresistive relative } \\
\text { pressure sensor } \\
\text { (Sensortechnics) }\end{array}$} & $0-100$ mbar & $\pm 0.1 \mathrm{mbar}$ & \\
\hline & & 0-350 mbar & $\pm 0.35 \mathrm{mbar}$ & \\
\hline & & $0-1$ bar & $\pm 1 \mathrm{mbar}$ & \\
\hline & & $0-2$ bar & \pm 2 mbar & \\
\hline & & $0-5$ bar & \pm 5 mbar & \\
\hline Rotational speed $(N)$ & Inductive sensor (Picoturn) & 0-200 $000 \mathrm{~K} \mathrm{rpm}$ & $\pm 200 \mathrm{~K} \mathrm{rpm}$ & $(200$ \\
\hline \multirow{2}{*}{ Air mass flow rate $(Q)$} & \multirow{2}{*}{$\begin{array}{l}\text { Thermal mass flow meter } \\
\text { (Proline } t \text { - mass65) }\end{array}$} & $0-0.005 \mathrm{~kg} / \mathrm{s}$ & $\pm 0.00075 \mathrm{~kg} / \mathrm{s}$ & $(0.00075 / \sqrt{3})$ \\
\hline & & $0.005-0.25 \mathrm{~kg} / \mathrm{s}$ & $\pm 1.5 \% \mathrm{Qkg} / \mathrm{s}$ & $([1.5 \% \times Q] / \sqrt{3}$ \\
\hline
\end{tabular}

TABLE 3

Different pinch constructions

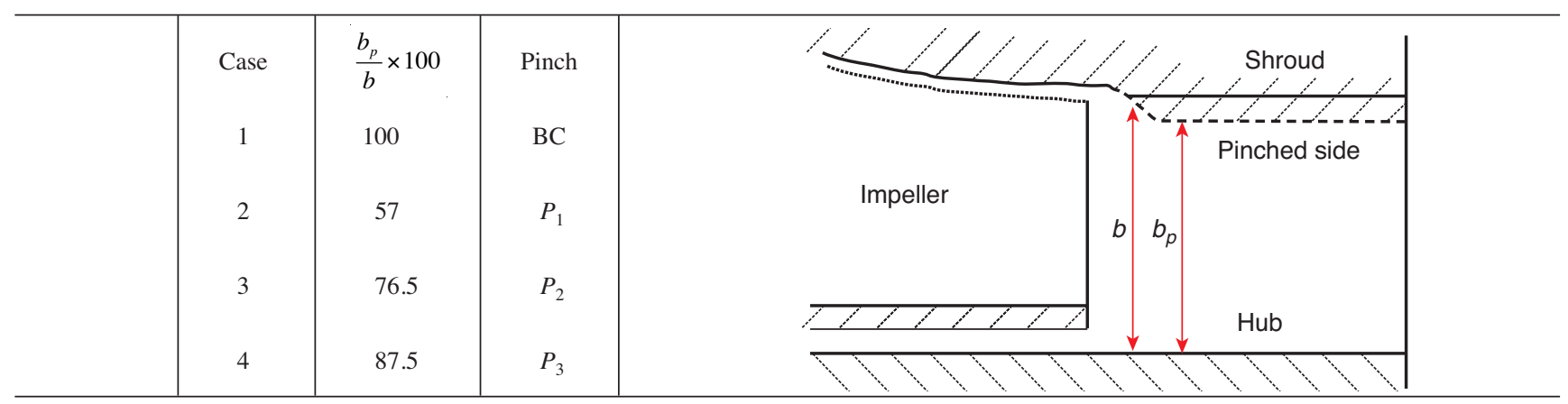

- to establish the most creditable basis for a practical variable geometry device.

Three different vaneless diffusers geometries were investigated by introducing pinches at the shroud side of the diffuser, to simulate a variable geometry diffuser which could be achieved through a system that will be proposed later. Table 3 shows the geometry of the three tested configurations, together with a 2D scheme to clarify. $P_{3}$ tested configuration is presented in Figure 2.

\section{Result and Interpretation}

As it can be seen from Figure 3, shrouded pinches have moved surge line to low flow rates, with small pinches having the smallest effect and highly pinched diffuser having the greatest improvement. On the other hand, this surge line shift is accompanied by a total pressure drop which increases with pinch increase.

Table 4, represents a quantitative comparison between improvements obtained when using a pinched diffuser compared to compressor basic characteristics at two different pressure ratios. As it can be seen, a 30\% increase in surge line can be obtained using $P_{1}$ at $T P R=2$.

Table 5 shows another way to look at the improvement obtained when using pinched diffuser. The total stable pressure increase for a corrected mass flow rate of $0.03 \mathrm{~kg} / \mathrm{s}$ and $0.02 \mathrm{~kg} / \mathrm{s}$ respectively. About 0.5 bar total stable pressure increase was obtained when mounting the $P_{1}$ configuration. 

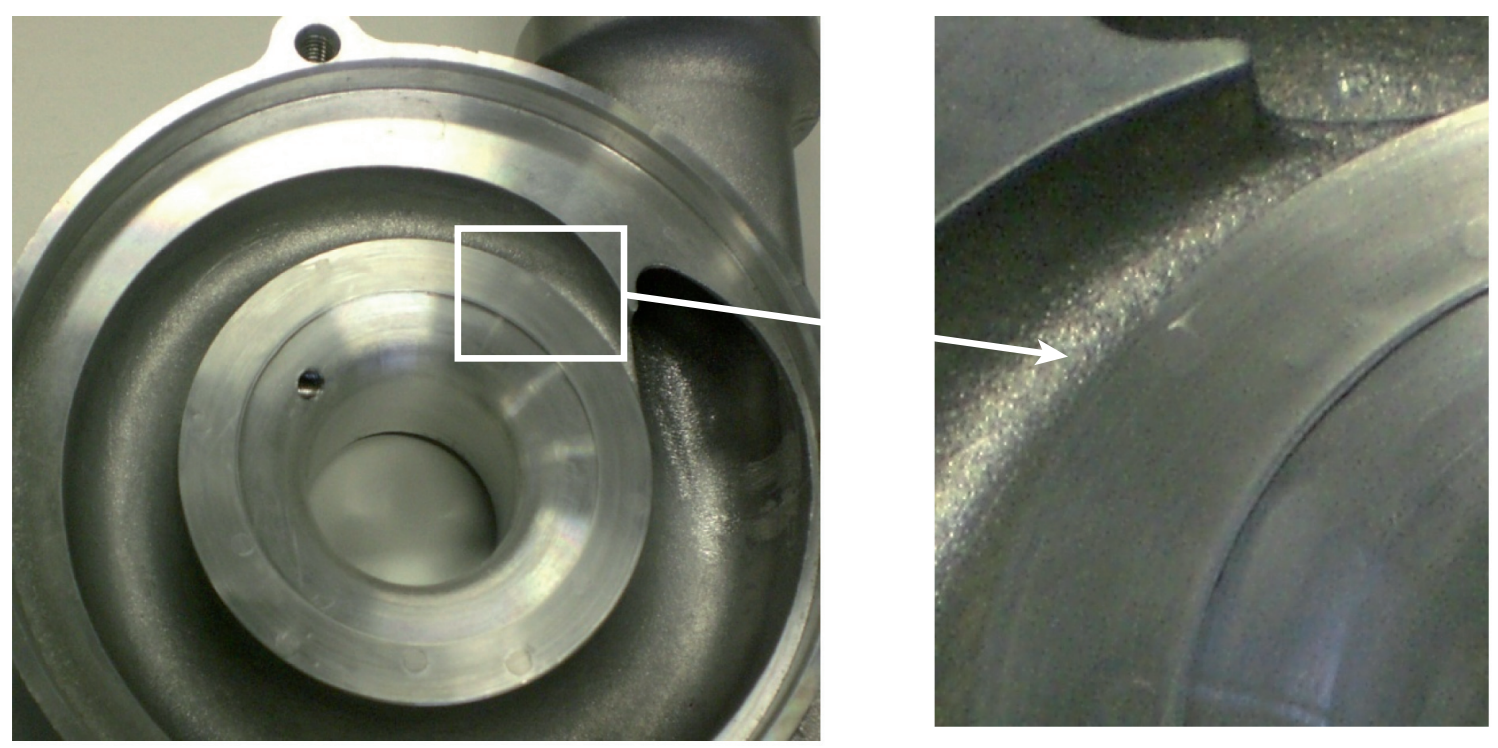

Figure 2

Tested pinched configuration. $P_{3}$ to the left and zoom to the right.

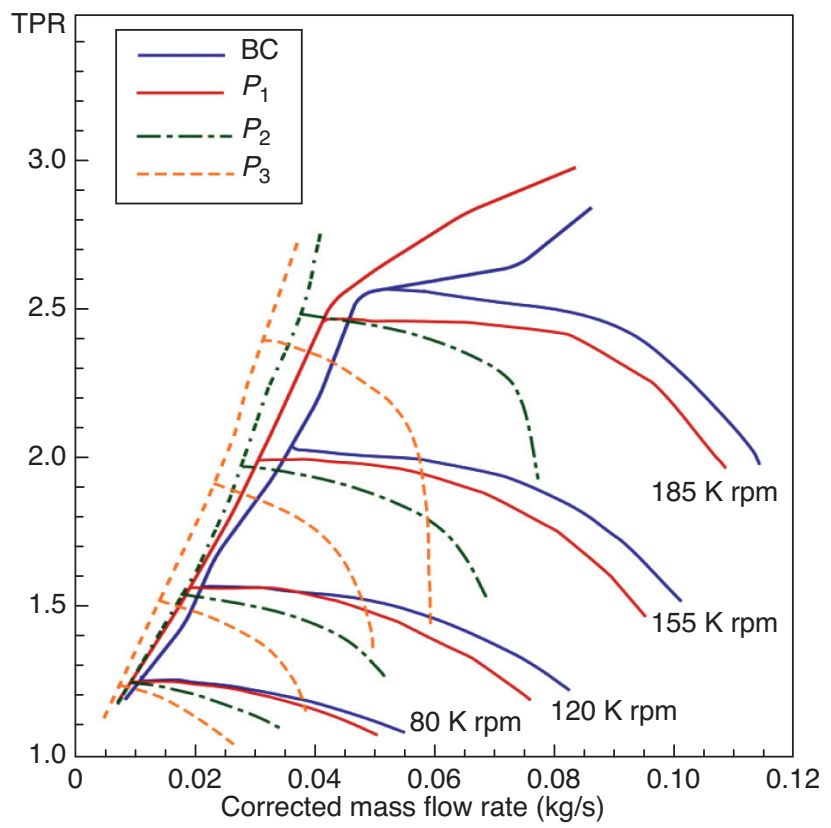

Figure 3

Compressor total pressure ratio using three different pinched configurations, and compared to basic characteristics.

TABLE 4

Surge line improvement for each of the pinch configurations compared to the compressor basic characteristics at $T P R=2$ and $T P R=2.5$

\begin{tabular}{l|c|c|c}
\hline Pinched diffuser & $P_{1}$ & $P_{2}$ & $P_{3}$ \\
\hline Surge line displacement $(\%), T P R=2$ & 30 & 17.4 & 11.4 \\
\hline Surge line displacement $(\%), T P R=2.5$ & 28.2 & 17.3 & 8.6 \\
\hline
\end{tabular}

TABLE 5

Total stable pressure increase when using pinched diffuser compared to the compressor basic characteristics at $T P R=2$ and $T P R=2.5$

\begin{tabular}{l|c|c|c}
\hline Pinched diffuser & $P_{1}$ & $P_{2}$ & $P_{3}$ \\
\hline$T P R$ increase (bar), at $0.03 \mathrm{~kg} / \mathrm{s}$ & 0.48 & 0.22 & 0.13 \\
\hline$T P R$ increase (bar), at $0.02 \mathrm{~kg} / \mathrm{s}$ & 0.25 & 0.1 & 0.09 \\
\hline
\end{tabular}

As it can be seen from Figure 4, using pinches has dropped the compressor isentropic efficiency at high flow rates. However, for pinched diffuser configurations $P_{2}$ and $P_{3}$, isentropic efficiency almost matches the efficiency of the baseline configuration at near surge line zone. A quantitative study is presented in Table 6 , where:

- $S_{1}$ is the surge point at $N=120 \mathrm{~K} \mathrm{rpm}\left(Q_{c}=0.0219 \mathrm{~kg} / \mathrm{s}\right)$,

- $S_{2}$ is the surge point at $N=150 \mathrm{~K} \mathrm{rpm}\left(Q_{c}=0.033 \mathrm{~kg} / \mathrm{s}\right)$,

- $S_{3}$ is the surge point at $N=185 \mathrm{~K} \mathrm{rpm}\left(Q_{c}=0.046 \mathrm{~kg} / \mathrm{s}\right)$.

The surge line move to low flow rate, can be interpreted in the following way:

- suppressing instabilities in the diffuser due to increasing the radial velocity and consequently the flow angle at the diffuser inlet, hence decreasing the critical flow angle;

- since a stage stall is a collective stall of different components, then suppressing the diffuser instabilities, may delay the stage stall and hence the system surge;

- more impeller uniform flow, due to improving impeller diffuser interaction. 


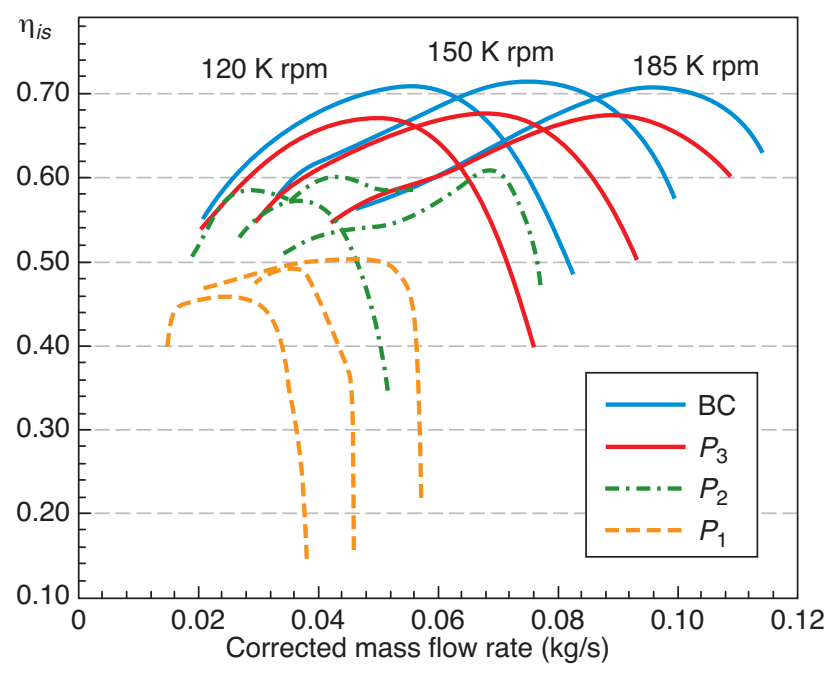

Figure 4

Compressor isentropic efficiency when using the three configurations compared to basic characteristics.

TABLE 6

Total to total isentropic efficiency at three pinch configurations, at three near surge points: $S_{1}, S_{2}$, and $S_{3}$

\begin{tabular}{l|c|c|c}
\hline Pinched diffuser & $P_{1}$ & $P_{2}$ & $P_{3}$ \\
\hline$\eta_{i s}$ decrease at $S_{1}$ & 15.9 & 3.2 & 1.4 \\
\hline$\eta_{i s}$ decrease at $S_{2}$ & 13.6 & 2.24 & 0.5 \\
\hline$\eta_{i s}$ decrease at $S_{3}$ & 10.5 & 2.1 & 0 \\
\hline
\end{tabular}

On the other hand, the pressure losses due to pinch mounting can be explained by the two following points:

- increase in friction losses due to increase in the diffuser radial velocity, due to reduction in flow area;

- losses due to dissipation of radial component of velocity in the volute.

The increase, in surge margin and total pressure stable functioning at low flow rates was accompanied by a high pressure drop at high flow rates. The pressure drop is caused by frictional losses increase due to increasing velocity, and radial energy losses in the volute.

We focused on the effect of applying the different configurations on the compressor performance and surge line in the near surge line zone. Hence, future industrial application can be to apply a variable geometry diffuser, where diffuser area can be reduced in real time near the surge line hoping to move surge to low flow rates.

\subsection{Effect of Diffuser J-Grooves on Compressor Performance and Surge Line}

Most of the studies done on shallow grooves agreed that the groove reverse flow rate critically evaluates the effectiveness of the grooves, since it is responsible of increasing diffuser inlet flow angle, due to the following effects [17]:

- flow in the grooves losses all its angular momentum;

- most of the groove flow re-enters into the main flow at the groove starting segment and thus increases the radial velocity near diffuser walls.

The groove reversed flow can be calculated using radial pressure gradient equations after substituting for the wall shearing stresses. Reverse flow is expressed by Gao et al. [17] as,

$$
m_{G}=2.87 \frac{v^{\frac{-1}{7}} \bar{C}_{\alpha}^{\frac{8}{7}} d^{\frac{12}{7}} w^{\frac{12}{7}} n}{(2 d+w)^{\frac{5}{7}} R^{\frac{4}{7}}}
$$

where $\overline{C_{\alpha}}$ denotes the average value of tangential velocity in the diffuser over the groove section, and $v$ air kinematic viscosity. According to Equation (1), the effectiveness of reverse flow in $J$-grooves is greatly determined by the following geometrical parameters:

- width of the groove, $w$,

- depth of the groove, $d$,

- and number of grooves, $n$.

Based on Equation (1), a combination between the different geometrical parameters, named $F$, to be the governing relation between groove parameters to control stall was proposed by Gao et al. [17]. The author also included the influence of the upstream impeller to make this parameter more meaningful, and therefore the impeller exit radius was used in Equation (2).

$$
F=\left(\frac{d}{R_{2}}\right)^{\frac{12}{7}}\left(\frac{w}{R_{2}}\right)^{\frac{12}{7}} \frac{n}{\left(\frac{2 d}{R_{2}}+\frac{w}{R_{2}}\right)^{\frac{3}{7}}\left(\frac{l}{R_{2}}\right)^{2}}
$$

Two configurations have been tested to study the effect on compressor performance and surge margin of $J$-grooves mounted in the diffuser casing wall (shroud side). Geometrical characteristics of tested $J$ grooves are shown in Table 7.

TABLE 7

Different groove constructions

\begin{tabular}{c|c|c}
\hline Case & Groove geometry parameter & Groove \\
\hline 1 & $n=12 ; w=3 ; d=0.3 ; l=11$ & $G R_{1}$ \\
\hline 2 & $n=6 ; w=3 ; d=0.3 ; l=11$ & $G R_{2}$ \\
\hline
\end{tabular}

Tested grooves geometrical characteristics are based on the afore mentioned discussions, and are as follows.

Grooves length was chosen to have the diffuser length. This decision was based on the work of Kurokawa et al. [16], who studied the effect on suppressing rotating stall of different groove lengths, and he concluded that only the longest groove totally suppress rotating stall even at zero flow rate. 

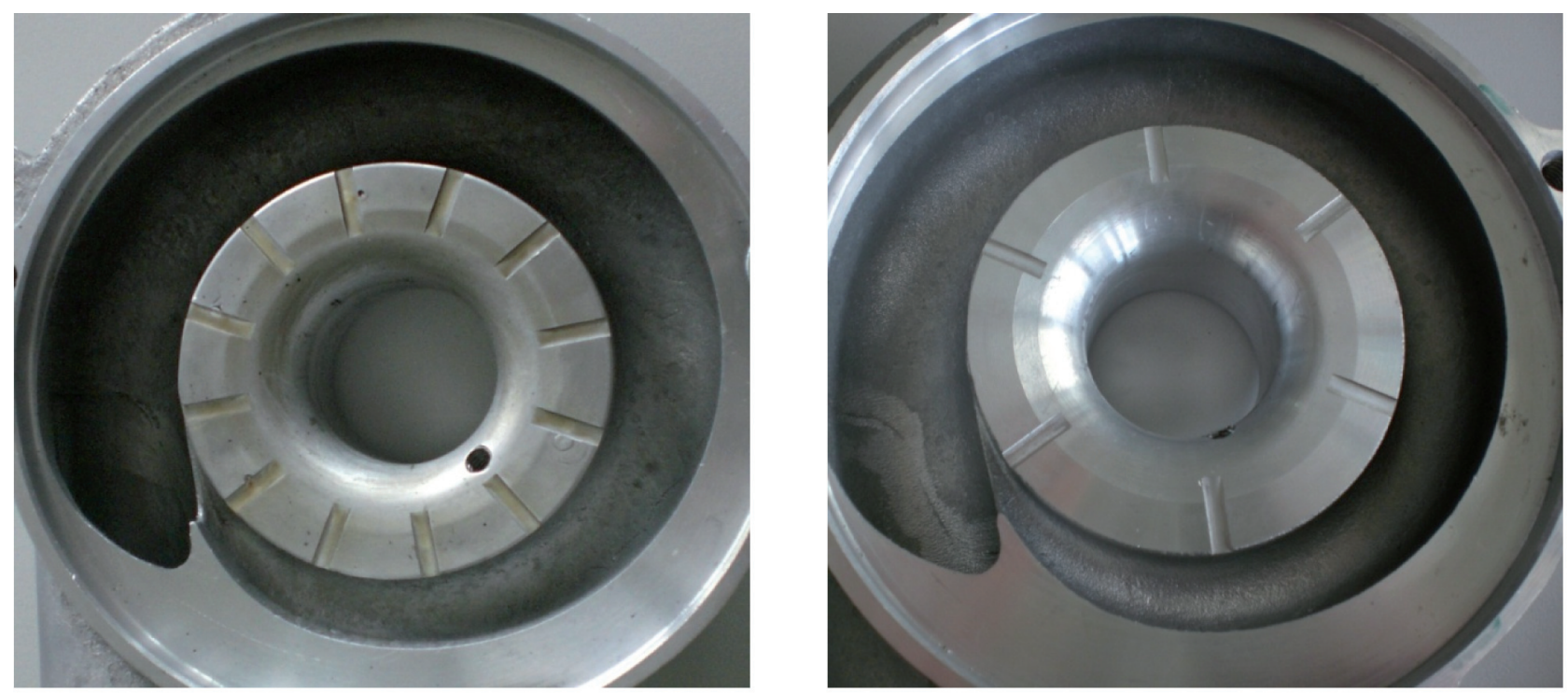

Figure 5

Tested $J$ grooves configurations. $G R_{1}$ to the left and $G R_{2}$ to the right.

For parameters $w, d$ and $n$, dimensioning was based on the work of Gao et al. [17] who concluded that no matter how $d, w$, and $n$ vary as long as the value of $F$ is not changed the effect of grooves would be approximately the same. Moreover, they added that the greater the value of $F$, the smaller the critical flow rate is, hence greater the stable margin of the diffuser. Figure 5 shows the two tested grooves $G R_{1}$ and $G R_{2}$.

For this study, we chose to study two different values of $F$ (big and small value). Limited by manufacturing constraints, $w$ and $d$ were not changed, and the value of $n$ was varied to change the value of $F$.

\subsubsection{Results and Interpretation: $\mathrm{GR}_{1}$ Configuration}

Figure 6 shows the effect on the compressor performance and surge line of $G R_{1}$ configuration. As it can be seen, the surge and choke lines move to low flow rates. Surge line shift can be explained by increase in diffuser operating range. This stability increase, delay the compressor stage stall.

The choke line move to low flow rate, can be explained by the high increase in the radial component at diffuser exit and choke may exist at the volute tongue due to high angle of attack which causes flow separation in the exit cone and downstream the tongue.

The surge line move to low flow rate was due to increasing diffuser stability by increasing radial velocity and consequently inlet diffuser angle.
The surge line move toward low flow rate is accompanied by high total pressure loss. This pressure loss can be explained by the following factors:

- increase in diffuser skin losses due to increase in surface area;

- loss in the volute of the kinetic energy associated with the increased velocity radial component in the volute.

Big $F$ values were advantageous in delaying diffuser instabilities. However, the surge line shift was accompanied by efficiency decrease, and total pressure drop.

\subsubsection{Results and Discussions: $\mathrm{GR}_{2}$ Configuration}

Interesting results were obtained when using $G R_{2}$ configuration. At high flow rates and almost all speeds, pressure increases accompanied by surge margin slight increase (Fig. 7). The Efficiency slight increase is to be taken prudently noticing the measurement accuracy which become high at high speeds [22].

The slight diffuser area increase was probably advantageous in improving impeller diffuser interaction. Hence, more uniform flow in the impeller and the diffuser. This can explain the pressure increase at high flow rates.

The slight surge line shift is probably due to tarden diffuser instabilities, due to radial velocity increase in the diffuser. However, this increase was lesser than that obtained for high $F$ values $\left(G R_{1}\right.$ configuration). 

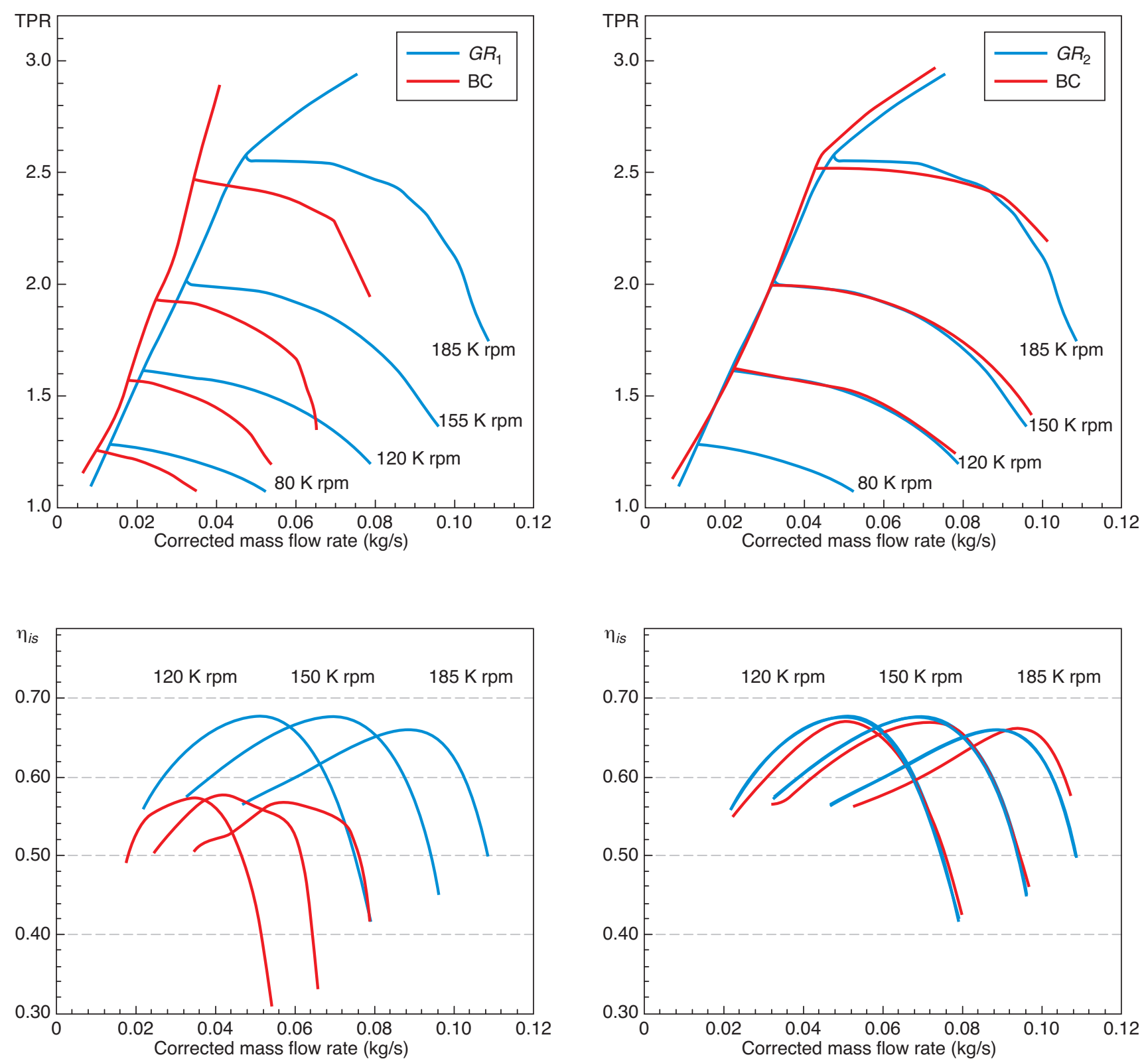

Figure 6

Effect on compressor performance and surge line of $G R_{1}$ configuration.

Figure 7

Effect on compressor performance and surge line of grooved system, $G R_{2}$.

\subsection{Synergy Effect of Pinched Diffuser and Grooves: GRP Configuration}

The idea behind the GRP configuration is to add two different techniques to increase radial velocity. GRP configuration is presented in Figure 8 and its geometrical characteristics in Table 8 .

\section{Results and Interpretation}

As it can be seen from Figure 9, results obtained are similar to those obtained when using $G R_{2}$ configuration, with much higher efficiency, pressure ratio increase at high flow rates, and more efficiency and pressure losses at low flow rates, compared to the same configuration. 


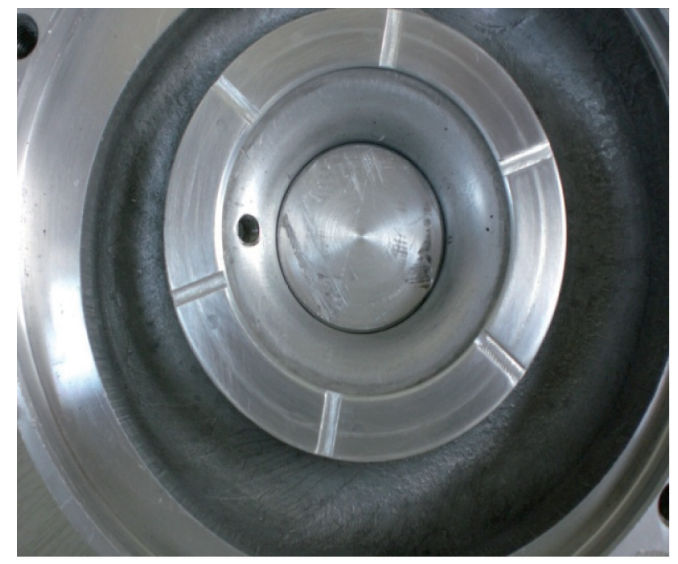

Figure 8

Tested grooves on pinched diffuser (GRP).

TABLE 8

Configuration geometry

\begin{tabular}{c|c|c}
\hline Groove geometry parameter & Pinch geometry & Configuration \\
\hline$n=6 ; w=3 ; d=0.3 ; l=9.5$ & $\frac{b_{p}}{b}=0.85$ & $\begin{array}{c}\text { Pinched shroud }+ \\
\text { grooves (GRP) }\end{array}$ \\
\hline
\end{tabular}

Efficiency increase at high flow rate is quite interesting. However, unfortunately we still have no exact explanation of this increase. It's highly possible that the GRP configuration improves impeller diffuser interaction, hence more uniform flow in these two components. CFD analysis together with local measurements are to be done in order to clarify the flow in and at the diffuser exit produced by the GRP configuration.

\section{EFFECT OF RETRACTING VOLUTE TONGUE ON COMPRESSOR PERFORMANCE AND SURGE LINE}

The effect of the tongue shape on the overall characteristics of the compressor is experimentally investigated in this section. The tongue was retracted and rounded, as presented in Table 9. Where $t$ is the clearance between diffuser and the tongue and $D_{3}$ is the diffuser diameter. $\alpha_{t g}$ is the tongue angle with respect to the tangential (Fig. 10).

\section{TABLE 9}

New volute tongue

\begin{tabular}{c|c|c}
\hline & $\frac{t}{D_{3}}$ & $\alpha_{t g}$ \\
\hline$T G_{1}$ & 0.085 & $27^{\circ}$ \\
\hline$T G_{2}$ & 0.125 & $44^{\circ}$ \\
\hline
\end{tabular}

Results and Discussion

Results obtained when retracting and rounding volute tongue can be resumed in the following 3 points (Fig. 11):
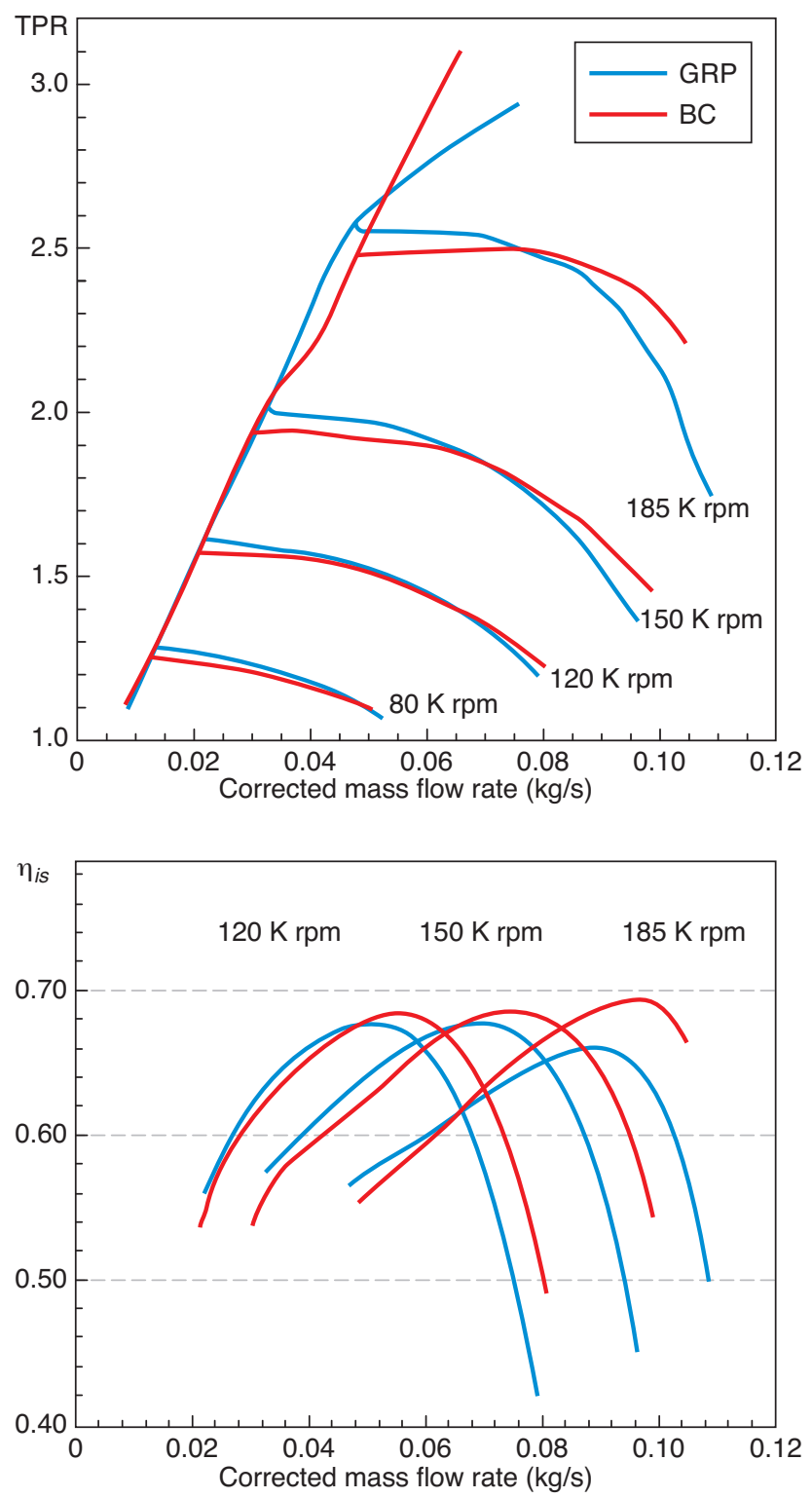

Figure 9

Effect on compressor performance and surge line of grooves mounted on a shrouded pinch diffuser, GRP.

- compression ratio slightly increases both at low and high flow rate while retracting and rounding the tongue, this increase becomes higher at high rotational speeds. A similar head increase was reported by Dong et al. [19] when retracting a tongue of a pump volute;

- the isentropic efficiency increases at middle flow rates;

- unless a very slight increase in the surge line at high rotational speed, surge line has not been affected by tongue retraction. Its worth noting that, Lipski (1979) [20] experiments on pump volute, showed that the pump 
a)

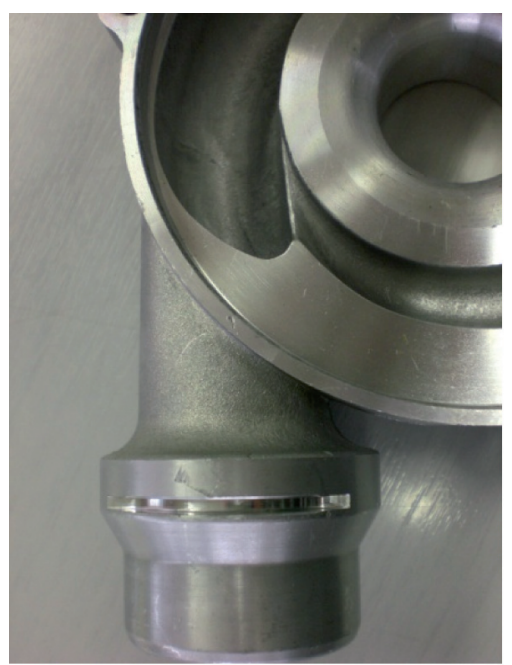

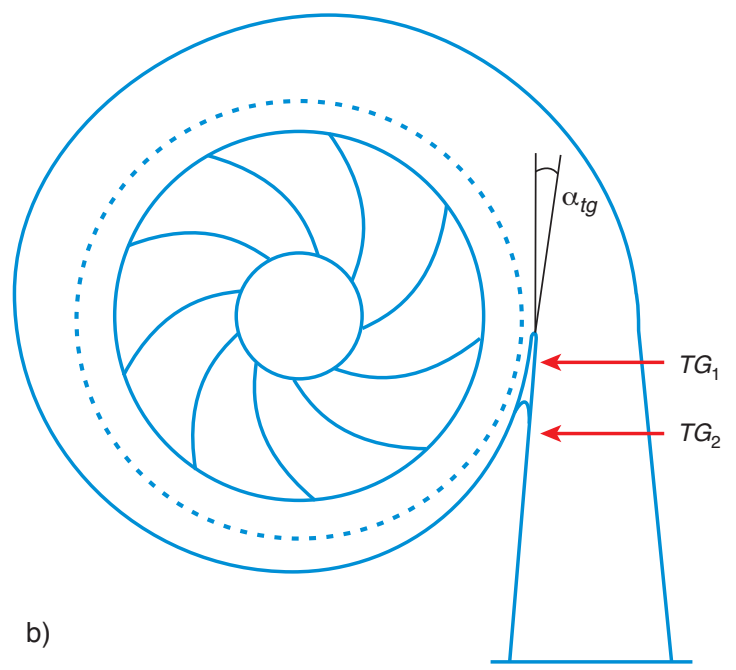

Figure 10

Tongue shape $T G_{2}$ compared to basic tongue shape $T G_{1}$, a) tested volute, b) 2D presentation.
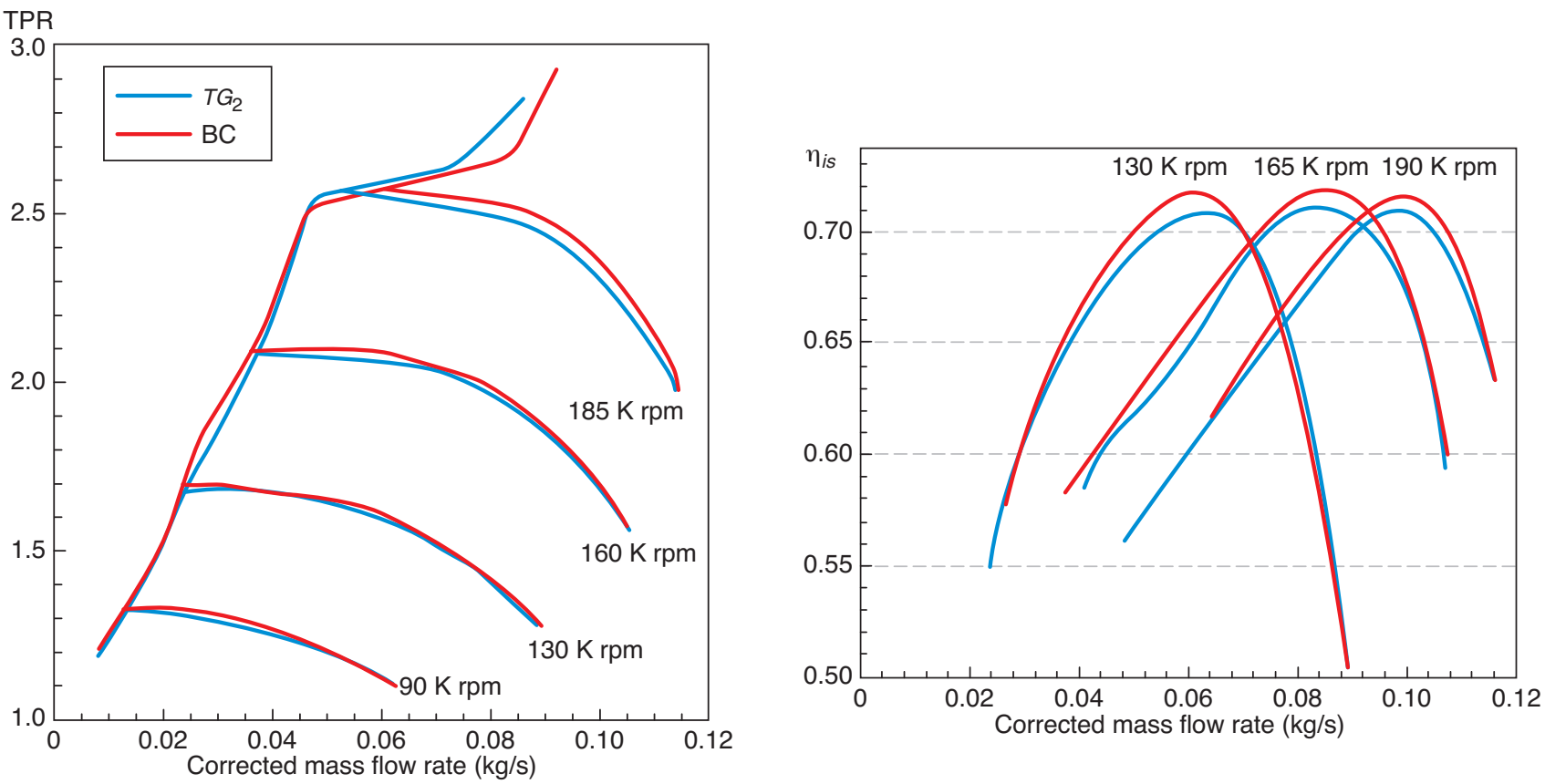

Figure 11

Compression ratio and isentropic efficiency with and without modified tongue.

efficiency at the design point was also increased by shortening of the tongue, which indicates the volute or the tongue were also mismatches.

Results can be explained in the following way:

- compression ratio increase can come from a more uniform pressure distribution in the tongue, a more uniform static pressure around the circumferential which creates a more uniform flow in the impeller or the diffuser. This same explanation can proof the stage efficiency increase;

- as discussed in Section 3, blockage at the tongue of the volute was believed to increase the circumferential pressure along the volute, the non uniformity may lead impeller or diffuser to operate unstably, or can amplify impeller or diffuser instabilities. However, it is not the volute that 
directly controls stall. This explanation is confirmed in this section. The volute tongue changes have not influenced the surge line.

\section{CONCLUSION}

Different pinched and grooved diffuser configurations are tested in this section. While these techniques are used in industrial compressor to suppress diffuser instabilities by increasing radial velocity in the diffuser at low flow rates, there is still a lack of information about their effect on turbocharger compressor.

While pinches were efficient in delaying diffuser instabilities, it creates high pressure and efficiency losses, due to friction losses increase in the diffuser. Reasonable area reduction is advantageous in improving impeller diffuser interaction.

Grooves are probably advantageous in delaying diffuser instabilities, hence shifting surge line to low flow rates. However, grooves number and dimensioning affect on compressor performance varies from surge line increase (high $F$ values) to slight surge line shift but efficiency and pressure ratio increase at high flow rates (for small $F$ values). This efficiency increase is probably due to impeller diffuser interaction.

To illustrate the effect of introducing variable geometry to the vaneless diffuser, different diffuser area reductions have been studied in this section. It has been showed that varying diffuser area can significantly move surge line to low flow rates. If a variable geometry diffuser can be machined so that it can decrease the diffuser area at near surge in real time, a great increase in surge operating range can be obtained.

In addition to increasing surge line, the introduction of a variable component, for reasonable values of diffuser area decrease $\left[\frac{b_{p}}{b}<0.7\right]$, can at least match the efficiency of the baseline configuration in this region.

Whitfield et al. [8] concluded that a greatest modification of compressor performance can be obtained if the hub side of the diffuser is modified. It will be interesting to study the effect of hub modifications. Unfortunately, this type of modifications is difficult to be done and was not tested due to machining constraints and complexity.

Further investigations are needed to better understand the different diffuser configuration test results. CFD analysis together with local measurements will be done to analyze flow in the diffuser, and its effect on the volute and compressor overall performance.

To better understand the effect of the volute circumferential pressure distribution on compressor surge line and performance, volute tongue was retracted and rounded. This results in compressor efficiency improvement at almost all flow rates.
Moreover, results indicate that the volute or the tongue were also mismatched. This is a very interesting point, since $1 \mathrm{D}$ analysis is almost used to design compressor volute, this simple approach is probably not sufficient to find out the optimum volute for a given compressor.

\section{REFERENCES}

1 Kyrtatos N., Watson N. (1980) Applications of aerodynamically induced pre whirl to small turbocharger compressor, ASME, $J$. Eng. Power 102, 934-950.

2 Galindo J., Serrano J.R., Margot X., Tiseira A., Schorn N., Kindl H. (2007) Potential of flow pre-whirl at the compressor inlet of automotive engine turbochargers to enlarge surge margin and overcome packaging limitations, Int. J. Heat Fluid Flow 28, 3, 374-387.

3 Rodgers C. (1990) Centrifugal compressor inlet guide vanes for increased surge margin, ASME paper 90-GT-158, 113, 696-702.

4 Whitfield A., Wallace F.R., Atkey C. (1975) Experimental and theoretical performance of a radial flow turbocharger compressor with inlet pre-whirl, IMechE 43/75.

5 Ishino M., Iwakiri Y., Bessho A., Uchida H. (1999) Effects of variable inlet guide vanes on small centrifugal compressor performance, ASME paper $99-\mathrm{GT}-157,2$.

6 Wimmer R., Steindl W. (2004) Vortex inlet vanes. DE10250302. 19.05.2004.

7 Barker D.L. (2005) A pre swirl generator a compressor and a method of imparting pre whirl to a gas flow, WO 2005/100798. 27.10.2005.

8 Whitfield A., Sutton A.J., Leonard H.J. (1991) The development of turbocharger compressors with improved surge margin, IMechE C433/063, 9-12.

9 Fischer F.B. (1988) Application of map width enhancement devices to turbocharger compressor stages, SAE paper 880794.

10 Hunzinker R., Dickmann H.P., Emmrich R. (2001) Numerical and experimental investigation of a centrifugal compressor with an inducer casing bleed system, Proc. IMechE A: J. Power Energy 215, 783-791.

11 Nikpour B. (2004) Turbocharger compressor flow range improvement for future heavy duty diesel engines, Thiesel 2004 conference on thermo-and fluid dynamics processes in diesel engines, September 7th-10th, 2004, Valencia (Spain).

12 Abdelhamid A.N., Bertrand J. (1980) Distinction between two types of self exited gas oscillations in vaneless radial diffusers, Can. Aeronaut. Space J. 105-117.

13 Turunen-Saaresti T., Grônman A.J., Jatinen A. (2009) Experimental study of pinch vaneless diffuser of centrifugal compressor, ASME Turbo EXPO 2009, GT2009-60162. Orlando.

14 Ludtke K. (1983) Aerodynamic tests on centrifugal process compressors - the influence of the vaneless diffusor shape, $J$. Eng. Power 105, 902-909.

15 Di Liberti J.-L., Wilmsen B., Engeda A. (1996) The effect of the vaneless diffuser width on the performance of a centrifugal compressor, Fluids Engineering Division Conference, ASME 237, 797-803.

16 Kurokawa J., Saha S.L., Matsui, J., and Imamura, H., A new passive device to suppress several instabilities in turbomachines by use of J-grooves, Proc. US-Japan Seminar: Abnormal Flow Phenomena in Turbomachines, Osaka, Japan, pp. 1-7 (1998-11). 
17 Gao C., Gu C., Wang T. (2009) Passive control of rotating stall in vaneless diffuser with radial grooves: detailed numerical study, ASME turbo Expo., Orlando, USA, 2009, Paper GT200959323, pp. 1225-1233.

18 Eynon P.A., Whitfield A. (2000) Pressure recovery in a turbocharger compressor volute, Proc. IMechE A. J. Power Energy 214, 6, 599-610.

19 Dong R., Chu S., Katz J. (1997) Effect of modification to tongue and impeller geometry on unsteady flow, pressure fluctuation and noise in a centrifugal pump, J. Urbomach., 506-515.

20 Lipski W. (1979) The influence of shape and location of the tongue of spiral casing on the performance of single stage radial pumps, Sixth Conference of Fluid Machinery, Budapest Akadamia Kiado, pp. 673-682.
21 Society of Automotive Engineering (SAE) Standard J1826, Turbocharger Gas Stand Test Code, SAE Press, Warrendale, PA (1995).

22 Mohtar H., Chesse P., Chalet D. (2011) Describing Uncertainties Encountered During Laboratory Turbocharger Compressor Tests, Experimental Techniques, Society for Experimental Mechanics, doi: 10.1111/j.1747-1567.2011.00734.x.

Final manuscript received in April 2011 Published online in November 2011 